\title{
11. Integrated mobility concepts in residential areas: challenges and opportunities of measures for sustainable urban mobility
}

\section{Benjamin Heldt, Rebekka Oostendorp and Julia Oehlert}

\subsection{INTRODUCTION}

Many people are used to the current car-oriented transport infrastructure. Thus, transforming transport requires the acceptance of sustainable transport policies by the general public (Banister, 2008) and, hence, local-scale planning for human beings, not for cars (Banister, 2011). This research focuses on an 'integrated mobility concept' (IMC), which is a coordinated plan for both urban development and transport planning on the neighbourhood scale, as opposed to a more strategic scale, and to concepts such as transit-oriented development. IMCs are typically applied in low-car and car-free neighbourhoods and include a wide range of measures. In theory, an IMC relies on a combination of alternative transport modes which mutually balances each mode's advantages and disadvantages and thereby address specific transport needs that traditionally require a personal vehicle (Mayer, 2018; Topp, 2017). Based on a review of several international and German housing projects, we can conclude that in practice IMCs often feature the following key elements: residential car (sharing) clubs, bike sharing, mobility-as-a-service such as transport planning apps, the physical integration of transport offers via so-called mobility hubs, the planning restriction and concentration of parking spaces in neighbourhood and collective parking garages, ${ }^{1}$ limited car accessibility, very good access to public transport, a high density and mix of land uses, as well as bicycle and pedestrian infrastructure.

The aim of developing an IMC is to minimize motorized personal transport and strengthen public transportation and active modes using systems of policies (for instance, measures and services) that aim at influencing the 
demand for mobility (Ammoser and Hoppe, 2006). In the context of growing urbanization, IMCs ideally reduce the traffic volume and speed, and promote space-efficient neighbourhoods by reducing the amount of land devoted to car infrastructure and repurposing it for active transport and other uses. Besides achieving positive effects on wellbeing, IMCs result in a decrease in costs for housing developers incurred by the construction of parking spaces, especially underground car parking (Topp, 2017).

Although IMCs appear to have many positive impacts, few studies analyse their effects on resulting transport, and no study has explored their effects on land consumption. Researchers have investigated IMCs implemented in car-free and low-car neighbourhoods either by examining overviews of several case studies at once (Baehler, 2019; Foletta and Henderson, 2016; Kushner, 2005; Melia, 2014; Scheurer, 2001; Nieuwenhuijsen et al., 2019) or by performing a more detailed analysis of single examples (Borges and Goldner, 2015; Loo, 2017; Ornetzeder et al., 2008; Nobis, 2003; Foletta and Field, 2011; Moser and Stocker, 2008). The results suggest that IMCs have positive effects on mode shares of public and active transport and decrease car ownership levels. However, the methods used in these studies rarely obtain information and statements from the actors involved in the development process of an IMC. Furthermore, they mostly investigate the effects of the concept as a whole, but not of the contribution of single measures. To our knowledge, Scheepers et al. (2014) were the only scholars who reviewed several studies analysing mobility interventions targeted at fostering more active transport. They found that such policies often have a positive impact, but they only investigated a limited number of measures.

What is more, the implementation of mobility interventions poses several challenges for the actors involved, which can hinder the success of IMCs. Local authorities, housing companies and planning agencies may face different issues and also might have different motivations for realizing mobility measures, leading to conflicts of interests.

Thus, the main question addressed by this research is: what do the practitioners think about the importance and contribution of these concepts, and what is required for their successful implementation? To address this research gap, we carried out a quantitative survey among three different groups of actors influencing urban mobility systems. The survey investigates expert knowledge on the importance of IMCs and different mobility-related measures in residential areas, on the effects of these measures on both traffic reduction and space efficiency, and on the reasons for implementing an IMC and the associated challenges. Following this brief introduction, section 11.2 provides a short overview of the survey methodology. In section 11.3, the results of the expert survey in terms of general experience, the expert assessment of measures as well as motives and challenges are described. Finally, we critically 
reflect on the results and the applied methodology and derive implications for policy and future research.

\subsection{SURVEY METHODOLOGY}

To acquire an initial understanding of the success factors and challenges associated with the realization of IMCs, we carried out a survey among German experts representing different stakeholders: local authorities and administrative bodies, housing companies, planning agencies and project developers (Oehlert, 2019). The survey sought to answer the following research questions:

1. What roles do IMCs play for practitioners, and to what extent do they already have experience in realizing them?

2. What are the expected impacts of IMCs and related measures on traffic volume and space-efficient land use according to the experts?

3. What challenges and opportunities are related to implementing IMCs in residential areas?

The questionnaire consists of 17 questions (Oehlert, 2019, p. 6). For most of these questions, a list of predefined items derived from literature and project reviews was provided (cf. Oehlert, 2019). The first part of the questionnaire asked for basic information on experts and their activities, such as institution, activity type, size of the city, and federal state. This was followed by a filter question on whether or not the respondent actually had experience with the planning and the implementation of mobility measures in new residential areas. If the answer was positive, the expert was asked to identify areas with previous experience, such as perceived impact of mobility measures, formal transport management tools, and reasons for the implementation of IMCs in new housing areas. Only respondents with experience in planning or developing mobility interventions were specifically asked to rate the contribution of different measures and neighbourhood mobility services to promoting space-efficient urban development and reducing traffic. In the final part of the questionnaire all experts were asked to answer questions on challenges of planning and implementing IMCs in new housing areas, and the impact of IMCs at the city level. The survey was conducted in May and June 2018 by emailing local authorities and housing and planning associations directly and via mailing lists. In total, 194 persons responded. Most participants represented public administrative bodies (40 per cent), planning agencies and project developers made up 27 per cent of the sample, and 20 per cent of the experts worked in housing companies. The remaining 13 per cent consisted of practitioners from research and other institutions which were not included in the evaluation. 


\section{$11.3 \quad$ RESULTS}

\subsubsection{General Experience in Implementing Mobility Measures}

In total, 135 experts (70 per cent of the respondents) were involved in projects implementing mobility measures in general. More specifically, more than half of the surveyed persons (56 per cent) were planning related developments when answering the questionnaire, and more than one-third ( 35 per cent) had already finished projects with IMCs. Among the analysed groups, about 60 per cent of experts either had implemented or had implemented and at the same time were planning further interventions. More experts from the housing industry than from the other groups had no experience at all related to IMCs. These results and, in particular, the high percentage of experts planning such projects at the moment show that neighbourhood-oriented mobility services are a recent and relevant topic for all of the actors surveyed.

Among the implemented measures mentioned (Figure 11.1), bicycle racks scored the highest and had been previously implemented or planned by 96 experts (75 per cent). This is because German building regulations require property developers to build bicycle racks with new buildings. Measures for reducing or mitigating the negative effects of personal motorized transport had been realized almost as often: carsharing for residents (66 per cent), charging infrastructure for electric vehicles (65 per cent), reduction of the number of parking spaces per housing unit (63 per cent) and parking management (60 per cent). Half of the respondents also had experience with mobility hubs. Fewer experts had implemented projects involving measures promoting bicycle and foot traffic such as bike and pedestrian paths, bicycle garages, bike sharing and cargo bike rental. While freight transport solutions are highly relevant and extensively discussed, measures such as central parcel collection points and micro-consolidation centres have only rarely been implemented to date. Fewer than 40 per cent of the experts had planned and implemented such measures in their urban logistics solutions.

\subsubsection{Assessment of the Impact of Mobility Measures on Transport and Space Efficiency}

Figure 11.1 shows the proportion of experts perceiving the measures to contribute positively to improving space efficiency and lowering traffic volume according to their personal assessments. Among all measures, reducing parking, car sharing stations for residents, and neighbourhood and collective parking garages were named by the highest number of experts as having a positive impact on space efficiency. The experts' statements show that the 


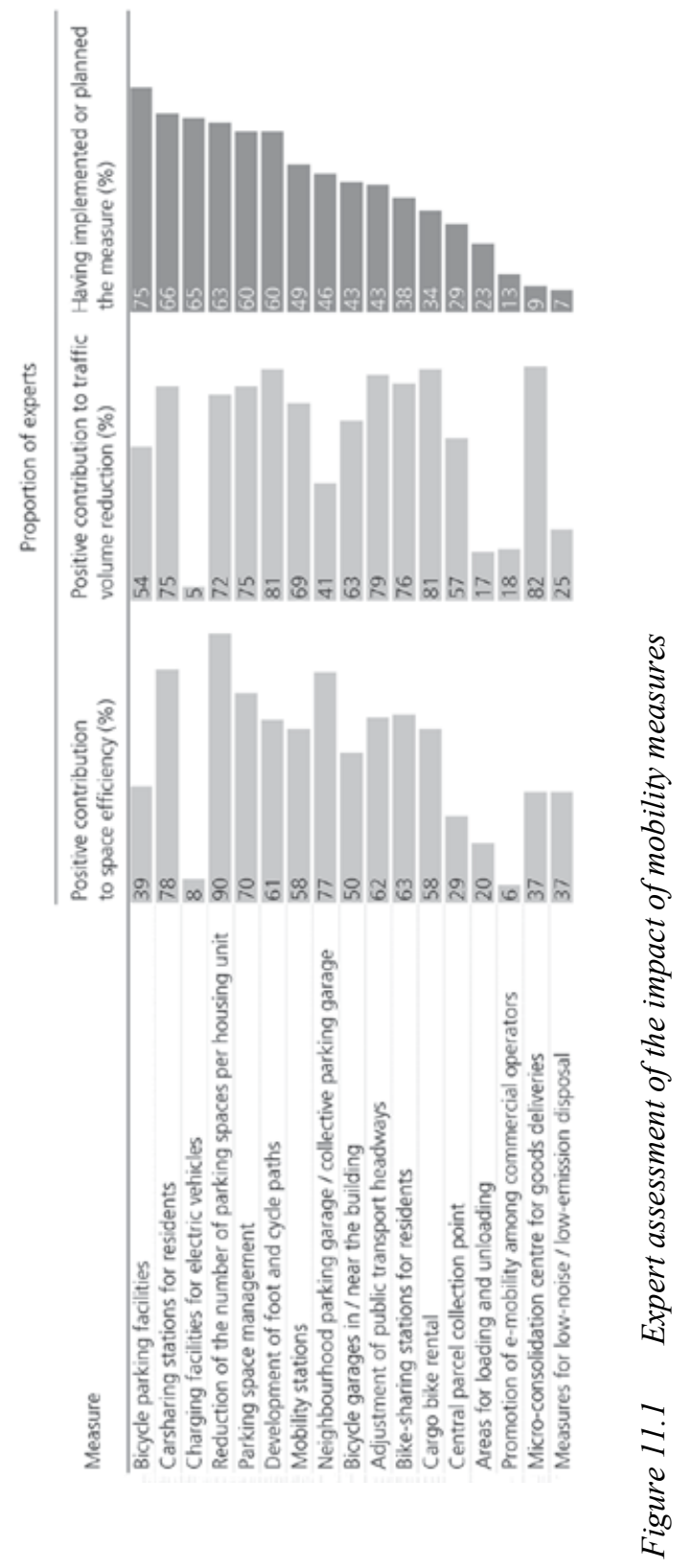


measures that most reduce traffic volume aim at promoting environmentally friendly modes or are related to freight transport. About 80 per cent of the experienced respondents ascribed a positive impact to adjusting bus frequency, increasing the number of pedestrian and cycle paths and implementing micro-consolidation centres and cargo bike rental. Bike sharing and car sharing stations as well as parking management are also considered to reduce traffic, with about 75 per cent of the experts seeing them as contributing positively. An interesting finding is that measures for promoting electric mobility, a highly topical aspect, are at the bottom of the ranking regarding their effect on land use efficiency or traffic volume, as almost no expert saw them as contributing positively. However, electric mobility may be associated with other potential positive impacts, such as the reduction of emissions, which were not investigated in this study.

The survey also revealed that often measures increasing space efficiency do not seem to help reduce traffic volume, as is the case for neighbourhood and collective parking garages. On the other hand, some measures that contribute to reducing motorized transport require space, such as micro-consolidation centres or bicycle garages. However, many experts recognize that some measures - such as car sharing stations, reduction of parking facilities, parking management, the extension of pedestrian and bicycle paths as well as the adjustment of public transport headways - contribute positively in both regards. The survey results indicate that there is not one single measure for developing sustainable neighbourhoods, but rather that a combination of measures restricting car usage and providing alternatives is important. In the survey, this is confirmed by 75 per cent of experts who agreed or agreed somewhat with the statement that mobility measures only work if applied together and not individually. Two-thirds also think that neighbourhood-related mobility offers and services should be part of an IMC. IMCs are associated with several positive impacts, while some effects are seen critically by many practitioners. Over 80 per cent of the experts agreed or agreed somewhat that these concepts can promote environmentally friendly modes, enhance quality of life, increase equity in mobility, reduce the negative effects of transport and decrease the level of motorization. The experts are more sceptical about whether such concepts can reduce parking shortage or costs (30 per cent disagreed somewhat or disagreed), increase building density ( 38 per cent) and, particularly, reduce freight traffic volumes (62 per cent). Finally, integrating a mobility concept into the planning process of new neighbourhoods from the start is important to prevent residents from relying on car-oriented mobility. However, our survey showed that only 47 per cent of experts agreed or agreed somewhat with the statement that 'Mobility measures should be part of each new residential development', although 78 per cent of the experts said that they are usually included in the planning process of new projects. 


\subsubsection{Implementation of IMCs: Motivations and Challenges}

In order to analyse the general conditions for IMC implementation, we asked experts to name their five main motivations and challenges when implementing IMCs (Figure 11.2). All experts from the three different groups pursued the goals of improving the quality of life in residential neighbourhoods and finding solutions to parking problems by implementing mobility measures and services. Respectively, 70 per cent of the respondents in each group were motivated by these goals, although the latter goal is more important for housing experts (Figure 11.2a). In contrast, local authorities want to shift motorized personal transport to environmentally friendly modes and satisfy the mobility needs of all population groups ( 90 per cent and 63 per cent respectively), while this is not so important for experts from housing companies. For the latter, it is more important to provide additional services for tenants and thereby increase the attractiveness of the housing (60 per cent), in comparison to other actors (less than 40 per cent).

Contrary to our assumption in the introduction, saving costs is not as an important factor for the experts. According to our survey, less than half of the experts in each group were motivated by this goal, for which there are several possible underlying reasons. Firstly, companies might not be aware of the cost reduction that can be achieved by dispensing with the construction of parking spaces. Secondly, the residential real estate market in Germany is currently driven by demand. Thus, more expensive apartments with parking spaces can still be let, and there is no need to reduce costs.

A closer look at the challenges that experts named reveals the factors that may prevent them from implementing IMCs in residential neighbourhoods or delay their realization (Figure 11.2b). The most frequently mentioned challenges differ more than the motivations mentioned by the experts. More than 50 per cent of the experts in each group of actors, with the exception of actors from housing companies, see major problems in the lack of will to realize measures. The results also reveal that planning agencies perceive the unclear legal framework as a major problem. Finally, 40 per cent of the experts from the housing sector see themselves mainly challenged by insufficient incentives, high costs and a lack of flexibility of local authorities. 
a)

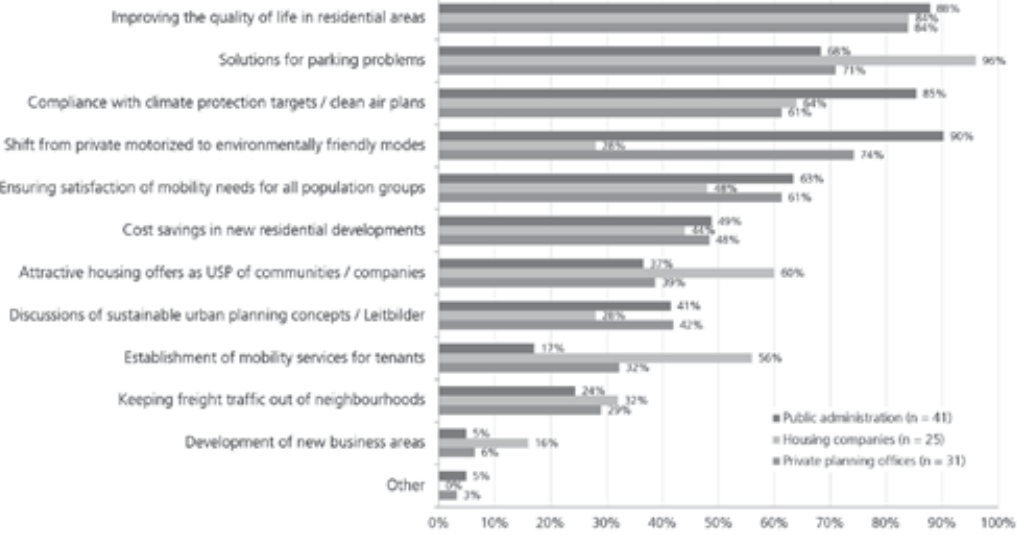

b)

Lack of wil to implement

Coordination needs between loxal authorites and housing comp.

Lack of acceptance by future residents

Rigid regulations of parking requirements

Undear legal tramework conditions

Lack of incentives

Land ownership stuation

Lack of flevibility of local authorities

Excessive costs
Lack of flexbility of housing companies

Unsultable site conditions

Long duration of the planning process

Eaboration of the concept

Lack of demand
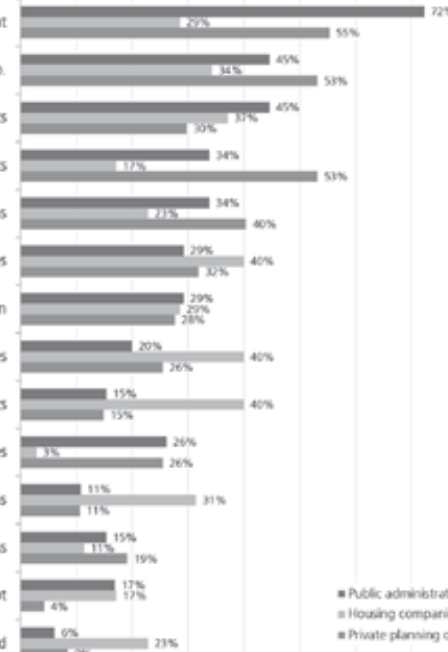

Other

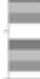

$\mathrm{R}^{12 \mathrm{~s}}$

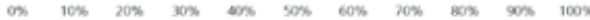

Note: USP - unique selling point.

Figure 11.2 (a) Experts' motivations for implementing mobility measures; and (b) Challenges associated with IMC implementation 


\subsection{SUMMARY AND IMPLICATIONS}

IMCs combine several mobility measures and services within a coordinated plan and are a core element for planning transport on the human scale, for instance in car-free and low-car neighbourhoods. Such concepts and related measures are expected to contribute to the sustainability of new residential neighbourhoods in terms of reducing traffic and efficiently using space. We conducted a survey, interviewing 194 experts to collect data on the experience of practitioners involved in developing IMCs. In general, the results of our survey corroborate the findings from other studies, pointing to recommending similar measures. According to the experts, some interventions decrease transport and improve space efficiency to a similar extent and should therefore be considered first in IMCs. However, most experts think that there is no single measure that both reduces traffic and improves space efficiency; rather, that measures might even have contradictory effects. Hence, the surveyed experts stress the importance of combining several measures in an integrated concept. In particular, restricting the number of parking spaces, on the one hand, and providing alternative mobility options, on the other, seems to support sustainable mobility behaviour. Surveyed practitioners mostly share the same motivations for implementing IMCs, but public authorities see IMCs as an instrument for shifting transport to more active modes, while housing companies view them as a marketing instrument. Regarding challenges, many respondents from housing companies perceive a lack of incentives and high costs as the main problems, whereas local authorities tend to mention a lack of will to implement them and the high demand for coordination. Moreover, it seems that, although actors have similar or complementary motivations, there are also conflicts of interest. Improving their collaboration, communication as well as the coordination of their activities could help to more effectively address challenges and eventually successfully implement projects.

This study corroborates other findings which have shown that in order to transform mobility, restrictions on the possession and use of cars are needed, combined with the provision of environmentally friendly alternatives (Nieuwenhuijsen, 2020). When designing such concepts, it is important to monitor them with empirical analyses such as residential surveys, data analyses and transport modelling, as well as to include expert views such as those reported here (Nieuwenhuijsen et al., 2019). Bringing expert knowledge and public ideas together to create IMCs can increase the acceptance of policies and interventions and contribute to transforming mobility to the human scale.

An additional learning from these findings is that when developing IMCs, stakeholders should first think about their objectives and then choose the corresponding mix of interventions. Depending on the measure, not all actors have 
the same scope of action, thus requiring them to collaborate. An additional underlying issue is that departments of transport and urban planning have often been separated in local jurisdictions for historical reasons (Bertolini, 2012). However, new planning positions have been created to bridge these gaps, such as climate protection and mobility managers. Furthermore, since only half of the surveyed experts think that residential projects should include IMCs, it seems important to include elements of IMCs not only in local planning instruments and regulations, but also in more general ones such as sustainable urban mobility plans. As IMCs combine different aspects with a new and complex approach, this could also help to solve problems with a legal framework and clear assignment of responsibilities.

This study has some limitations. The majority of the sample of experts came from cities and urban agglomeration areas, in particular from Berlin where local conditions differ from many other cities, particularly medium-sized cities, due to the city's high population growth and rising housing prices. This may have had an impact on the assessment of measures. Due to the federal system in Germany, the legislation regarding different measures, such as parking requirements for new housing, also varies. Besides the local specifics, the survey did not collect sufficient information on the experts, such as their experience, age, position or role, which would help to contextualize the results. Finally, measures that were not specified in the lists of items in the survey could not be rated, and thus the survey might be somewhat biased, although the choice 'other' was not frequently used.

Acceptance of sustainable mobility by the public is necessary for people to change their mobility behaviour. This can be achieved by demonstrating interventions and individual marketing on a local scale (Banister, 2008, 2011). Future studies should thus address whether and to what extent including residents in the planning process can increase an IMC's acceptance, for example by showing residents the available alternatives for their daily mobility as well as ways of using saved space differently. Studies obtaining expert knowledge should analyse whether the experts' responsibilities in institutions and level of experience influence their assessment of measures and IMCs in general. More qualitative research such as focus groups or experimental games could bring further insights into the actors' underlying motivations and perceived challenges. The complex interactions between the stakeholders should also be further investigated by applying social network analysis to the planning process of an IMC (Eräranta and Mladenović, 2020). Finally, we would learn much from a broad international expert survey or review in order to understand how IMCs are treated in different cultural contexts. 


\section{NOTE}

1. Throughout the text we use this term to refer to multi-level parking garages that cater to the needs of neighbourhood residents (German: Quartiersgarage). Visitors can possibly also use such facilities temporarily; however, their purpose is to provide long-term parking for residents near their homes.

\section{REFERENCES}

Ammoser, H., and Hoppe, M. (2006). Glossar Verkehrswesen und Verkehrswissenschaften: Definitionen und Erläuterungen $\mathrm{zu}$ Begriffen des Transport-und Nachrichtenwesens, Dresden, Germany: Technische Universität Dresden Institut für Wirtschaft und Verkehr.

Baehler, D. (2019). Living in a car-free housing development - motivations and mobility practices of residents in nine developments in Switzerland and Germany. Dissertation, Lausanne, Switzerland: Université de Lausanne.

Banister, D. (2008). The sustainable mobility paradigm. Transport Policy, 15, 73-80.

Banister, D. (2011). Cities, mobility and climate change. Journal of Transport Geography, 19, 1538-1546.

Bertolini, L. (2012). Integrating mobility and urban development agendas: a manifesto. disP-The Planning Review, 48(1), 16-26.

Borges, B.F.D.S., and L.G. Goldner (2015). Implementation of car-free neighbourhoods in medium-sized cities in Brazil, a case study in Florianópolis, Santa Catarin, International Journal of Urban Sustainable Development, 7(2), 183-195.

Eräranta, S. and Mladenović, M.N. (2020). Networked dynamics of knowledge integration in strategic spatial planning processes: a social network approach. Regional Studies, 1-13. https://rsa.tandfonline.com/doi/full/10.1080/00343404.2020.1739637 \#.YKFTI6gzY2w.

Foletta, N., and Field, S. (2011). Europe's Vibrant New Low Car(bon) Communities. New York: ITDP Europe.

Foletta, N., and Henderson, J. (2016). Low Car(bon) Communities: Inspiring Car-Free and Car-Lite Urban Futures. London, UK and New York, USA: Routledge.

Kushner, J.A. (2005). Car-free housing developments: towards sustainable smart growth and urban regeneration through car-free zoning, car-free redevelopment, pedestrian improvement districts, and new urbanism. UCLA Journal of Environmental Law and Policy, 23(1), 1-25. https://escholarship.org/uc/item/86g8p4w5.

Loo, B.P. (2017). Realising car-free developments within compact cities. Proceedings of the Institution of Civil Engineers: Municipal Engineer, UK.

Mayer, C.A. (2018). Moderne Mobilitätskonzepte in der städtebaulichen Quartiersentwicklung. Recht, Automobil, Wirtschaft, 2, 137-129.

Melia, S. (2014). Carfree and low-car development. In: Stephen Ison and Corinne Mulley (eds), Parking Issues and Policies (pp. 213-233). Bingley: Emerald Group Publishing.

Moser, P. and Stocker, E. (2008). Autofreies Wohnen - Evaluierung der Mustersiedlung in Wien-Floridsdorf. Vienna, Austria: SRZ Stadt+Regionalforschung.

Nieuwenhuijsen, M. (2020). Urban and transport planning pathways to carbon neutral, liveable and healthy cities: a review of the current evidence. Environmental International, 140. DOI: https://doi.org/10.1016/j.envint.2020.105661. 
Nieuwenhuijsen, M., Bastiaanssen, J., Sersli, S., Waygood, E.O.D. and Khreis, H. (2019). Implementing car-free cities: rationale, requirements, barriers and facilitators. In: Mark Nieuwenhuijsen and Khreis, Haneen (eds), Integrating Human Health into Urban and Transport Planning (pp. 199-219). Cham, Switzerland: Springer.

Nobis, C. (2003). The impact of car-free housing districts on mobility behavior - case study. WIT Transactions on Ecology and the Environment, 67, 701-710.

Oehlert, J. (2019). Integrierte Mobilitätskonzepte in Wohnquartieren. Chancen und Herausforderungen bei der Umsetzung von quartiersbezogenen Mobilitätsangeboten aus Sicht von Kommunen und Wohnungsunternehmen. Master's thesis, Technische Universität Berlin, Berlin.

Ornetzeder, M., Hertwich, E.G., Hubacek, K., Korytarova, K., and Haas, W. (2008). The environmental effect of car-free housing: a case in Vienna. Ecological Economics, 65(3), 516-530.

Scheepers, C.E., Wendel-Vos, G.C.W., den Broeder, J.M., van Kempen E.E.M.M., van Wesemael, P.J.V., and Schuit, A.J. (2014). Shifting from car to active transport: a systematic review of the effectiveness of interventions. Transportation Research Part A, 70, 264-280.

Scheurer, J. (2001). Urban ecology, innovations in housing policy and the future of cities: Towards sustainability in neighbourhood communities. Dissertation, Murdoch University, Australia.

Topp, H.H. (2017). Neue Mobilität und alte Stellplätze. Straßenverkehrstechnik, 6, 391-394. 